\title{
PENGEMBANGAN MEDIA PEMBELAJARAN BERBASIS ANDROID MATA PELAJARAN DESAIN GRAFIS KELAS X
}

\author{
Joko Kuswanto \\ Program Studi Informatika, Fakultas Teknik dan Komputer, Universitas Baturaja \\ jokokuswanto@unbara.ac.id \\ Jl. Ki Ratu Penghulu No. 02301 Karang Sari Telepon (0735) 326122 Fax. 321822 \\ Baturaja - 32113 OKU Sumatera Selatan
}

\begin{abstract}
Abstrak
Berkembangnya teknologi informasi dan komunikasi seperti android belum dimanfaatakan untuk menunjang proses pembelajaran. Sebagian besar guru dan siswa hanya menggunakan android untuk membuka jejaring sosial atau game. Semestinya kemajuan teknologi seperti android ini bisa dimanfaatkan dalam proses pembelajaran. Penelitian ini bertujuan untuk mengembangkan media pembelajaran berbasis android pada mata pelajaran desain grafis kelas X. Jenis penelitian ini merupakan penelitian pengembangan. Tahapan pengembangan media pembelajaran berbasis android menggunakan model prosedural. Berdasarkan beberapa tahapan pengujian media yang dilakukan kepada para ahli: ahli media $(78,30)$, ahli desain (78), dan ahli materi (80 dengan kriteria kelayakan Baik. Pengujian kepada peserta didik: skala perorangan (80), skala kecil $(80,05)$, dan skala lapangan $(80,5)$ dengan kriteria Baik Sekali. Jadi dapat disimpulkan bahwa media pembelajaran berbasis android ini sudah baik dan layak diterapkan dalam pembelajaran desain grafis di kelas $\mathrm{X}$.
\end{abstract}

Kata kunci: pengembangan, android, desain grafis

\begin{abstract}
The expansion of the information technology and communication as android yet to be fully developed to support a learning process. The majority of teachers and students only use android to open social network or game. Should have been progress this technologies such as android can be used in the process of learning. This study aims to develop android-based learning media on the subjects of graphic design class $X$. This research is research development. Stage development android-based learning media use the model procedural. Based on several stages of testing media was being done to experts: media experts $(78,30)$, the design (78), and the matter (80) with criteria feasibility good. Testing to students: one-toone (80), small group (80,05), and field test $(80,5)$ with criteria verry well. So can conclude that android-based learning media is good and should be applied in learning of graphic design class $X$.
\end{abstract}

Keywords: development, android, graphic design 


\section{PENDAHULUAN}

Proses pembelajaran merupakan suatu usaha dalam membelajarkan siswa yang terdiri dari komponen yang saling berhubungan meliputi: tujuan, materi, metode dan evaluasi untuk menentukan media, metode dan strategi pembelajaran yang tepat.

Media pembelajaran merupakan berbagai macam jenis komponen dalam lingkungan siswa yang dapat merangsang siswa untuk belajar walaupun bersifat menyalurkan pesan dan dapat merangsang pikiran, perangsang kemauan siswa sehingga dapat mendorong terjadinya proses belajar mengajar [(Diamar dkk, 2019). Media sebagai perantara dalam rangka memperlancar pencapaian tujuan dari pelaksanaan pendidikan. Media pembelajaran harus yang bersifat menyalurkan pesan dan dapat merangsang pikiran, dan kemauan siswa sehingga dapat mendorong terjadinya proses belajar pada dirinya.

Pada proses pembelajaran tersebut dibutuhkan seorang pendidik mampu mengintegrasikan seperti teknologi informasi dan komunikasi seiring dengan perkembangan zaman. Sebagai seorang pendidik dituntut untuk dapat secara kreatif mendesain suatu bahan ajar yang memungkinkan peserta didik dapat secara langsung memanfaatkan sumber belajar yang tersedia (Kuswanto, 2019). Guru dituntut untuk lebih kreatif dan inovatif dalam memilih sumber belajar, media ajar yang baik agar tercipta kegiatan pembelajaran yang lebih aktif, kreatif, inovatif, dan menyenangkan sehingga tercipta multi interaksi di kelas (Sefriani \&
Wijaya, 2019). Dengan penggunaan media secara kreatif oleh guru akan memungkinkan siswa untuk belajar lebih baik dan mampu meningkatkan perhatian dan pemahaman siswa dalam proses pembelajaran.

Berkembangnya teknologi informasi dan komunikasi saat ini, menjadikan proses pembelajaran dapat dilakukan dimana saja dan kapan saja misalnya pembelajaran berbasis android (Kuswanto, 2019). Android merupakan generasi baru platform mobile berbasis linux yang mencakup sistem operasi, middleware, dan aplikasi (Sari, 2018). Diharapkan dengan adanya media pembelajaran berbasis android dapat membangkitkan motivasi belajar siswa serta memungkinkan siswa dapat belajar mandiri sesuai dengan kemampuan dimanapun dan kapanpun.

Akan tetapi pemanfaatan dari kemajuan teknologi tersebut belum terlihat dalam pembelajaran. Berdasarkan fenomena yang terjadi saat pembelajaran di dalam kelas adalah proses pembelajaran yang dilakukan guru hanya menggunakan media buku teks yang berisikan materi dengan beberapa gambar. Penggunaan media lain seperti media berbasis android (handphone) belum dimanfaakan. Padahal, guru dan siswa sudah memiliki handphone berbasis android namun belum dimanfaatkan untuk menunjang proses pembelajaran. Sebagian besar guru dan siswa hanya menggunakan android untuk membuka jejaring sosial atau game. Semestinya kemajuan teknologi seperti android ini bisa dimanfaatkan dalam proses pembelajaran. 
Berdasarkan paparan di atas perlu adanya media pembelajaran berbasis android pada mata pelajaran desain grafis kelas X. Media pembelajaran tersebut dapat dijadikan media belajar bagi peserta didik baik disekolah maupun diluar sekolah, serta dapat digunakan oleh pendidik sebagai media pembelajaran dalam proses belajar mengajar. Selain itu dengan aplikasi ini siswa diarahkan agar lebih memanfaatkan smartphone yang mereka miliki tidak hanya untuk berkomunikasi namun juga untuk ranah pendidikan.

\section{Media Pembelajaran}

Media pembelajaran adalah salah satu faktor yang dapat mempengaruhi hasil belajar peserta didik, dengan menggunakan media pembelajaran, materi dapat disampaikan lebih jelas dan menarik sesuai dengan tujuan pembelajaran (Puspitaningrum dkk, 2019). Dengan adanya media pembelajaran dapat membangkitkan motivasi belajar siswa serta memungkinkan siswa dapat belajar mandiri sesuai dengan kemampuan dimanapun dan kapanpun (Kuswanto, 2019).

\section{Android}

Smartphone atau yang sering disebut dengan android adalah sebuah sistem operasi untuk smartphone dan tablet. Sistem operasi dapat diilustrasikan sebagai jembatan antara peranti (device) dan penggunaannya, sehingga pengguna dapat berinteraksi dengan device-nya dan menjalankan aplikasi-aplikasi yang tersedia pada device. Android merupakan generasi baru platform mobile berbasis linux yang mencakup sistem operasi, middleware, dan aplikasi (Menrisal \& Utami, 2019).

\section{Desain Grafis}

Desain grafis adalah salah satu bentuk seni lukis (gambar) terapan yang memberikan kebebasan kepada sang desainer (perancang) untuk memilih, menciptakan, atau mengatur elemen rupa, seperti ilustrasi, foto, tulisan, dan garis di atas suatu permukaan dengan tujuan untuk diproduksi dan dikomunikasikan sebagai sebuah pesan (Jafnihirda dkk, 2019).

\section{METODE PENELITIAN}

Metode yang digunakan dalam penelitian ini adalah penelitian pengembangan. Merupakan penelitian yang berorientasi untuk mengembangkan dan memvalidasi produk-produk yang digunakan dalam pendidikan (Borg \& Gall, 2003). Pengembangan media pembelajaran berbasis android ini menggunakan model prosedural yaitu model yang bersifat deskriptif, menunjukkan langkah-langkah yang harus diikuti untuk menghasilkan produk (Putra, 2011). Langkah-langkah prosedur pengembangan meliputi: tahap perancangan, produksi, dan evaluasi (Warsita, 2008).

Subjek dalam penelitian ini yaitu pada tahap awal dilakukan validasi oleh expert (ahli desain, media, dan materi). Kemudian dilanjutkan uji coba produk skala perorangan, uji coba kelompok kecil dan uji lapangan. Teknik pengumpulan data dalam penelitian ini menggunakan 
angket. Angket digunakan untuk memperoleh informasi serta data untuk mengukur kelayakan produk yang dihasilkan.

Untuk menghitung persentase tiaptiap instrument dari pengujian skala besar/lapangan menggunakan rumus sebagai berikut (Sudijono, 2012)

$$
\mathrm{P}=\frac{f}{N} \times 100 \%
$$

Keterangan:

$\mathrm{f}=$ Frekuensi yang sedang dicari persentasenya

$\mathrm{N}=$ Number of case (jumlah frekuensi/banyaknya individu)

$\mathrm{P}=$ Angka persentase

\section{HASIL PENELITIAN DAN}

\section{PEMBAHASAN}

\section{Hasil Penelitian}

Sesuai dengan langkah-langkah pengembangan yang telah dipilih, dihasilkan rancangan, produksi dan evaluasi sebagai berikut:

a. Tahap rancangan: pada tahap rancangan didapatkan hasil analisis kebutuhan berupa materi dan silabus mata pelajaran sesuai dengan kurikulum. Dilanjutkan dengan penyusunan naskah (storyboard).

b. Tahap produksi: pada tahap produksi, media yang dikembangkan berupa media audiovisual yaitu penggabungan antara teks, suara, gambar dan animasi.

c. Tahap evaluasi: pada tahap ini evaluasi pramaster terdiri dari evaluasi ahli, perorangan, dan kelompok kecil.

Dilanjutkan dengan uji coba lapangan.

Hasil akhir dari penelitian ini adalah pengembangan media pembelajaran berbasis android yang digunakan sebagai media pembelajaran. Aplikasi terdiri dari halaman-halaman yang saling terhubung, adapun tampilannya adalah sebagai berikut:

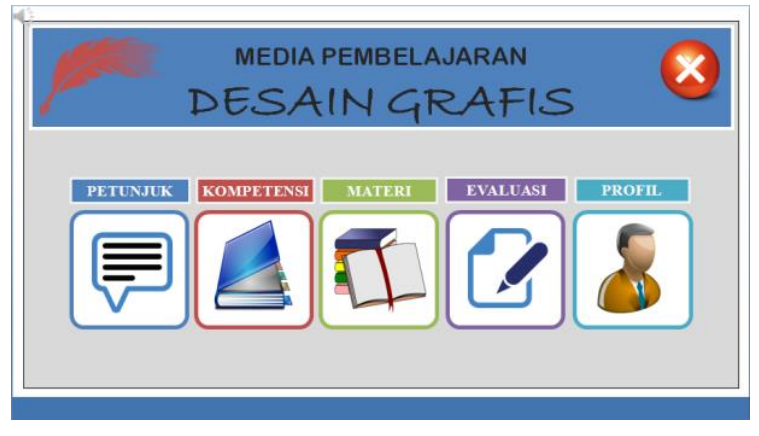

Gambar 1. Tampilan Utama

Gambar 1 merupakan halaman yang berisi tombol yang berfungsi untuk mempermudah pengguna dalam menjalankan atau mengakses tampilan yang diinginkan. Tombol-tombol yang berada di halaman utama tersebut antara lain Petunjuk, Kompetensi, Materi, Evaluasi, dan Profil.

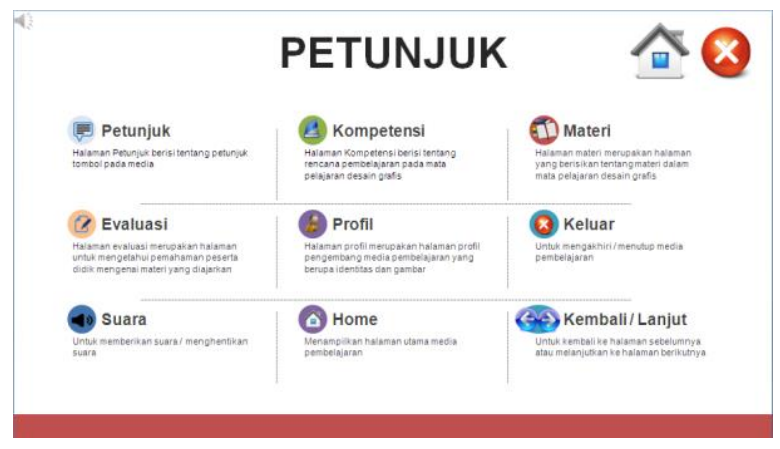

Gambar 2. Tampilan Petunjuk 
Dapat dilihat pada Gambar 2 yaitu Halaman petunjuk yang berisi informasi mengenai petunjuk umum cara pemakaian program yaitu mengenai fungsi-fungsi tombol atau tampilan yang digunakan dalam program ini. Kemudian Gambar 3 menunjukkan halaman kompetensi yang berisikan informasi mengenai Kompetensi Inti, kompetensi dasar yang dibuat. Isi dari Kompetensi Inti dan Kompetensi Dasar dalam program ini disesuaikan dengan silabus pembelajaran desain grafis.

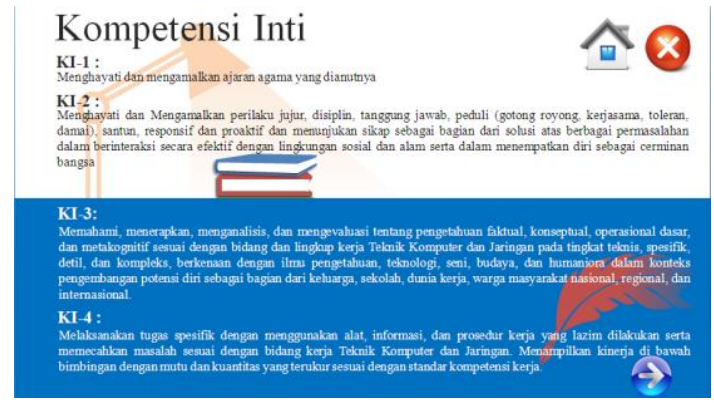

Gambar 3. Tampilan Kompetensi

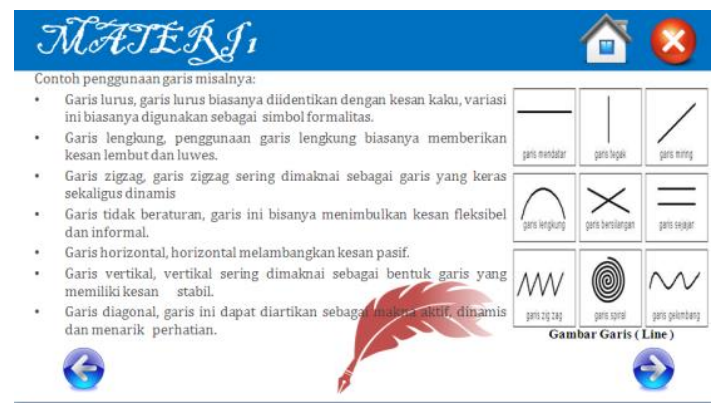

Gambar 4. Tampilan Materi

Gambar 4 memperlihatkan tampilan menu materi. Halaman materi ini merupakan sub menu dari halaman menu utama. Adapun dalam halaman materi ini terdapat menu untuk menghubungkan ke materi berupa teori.

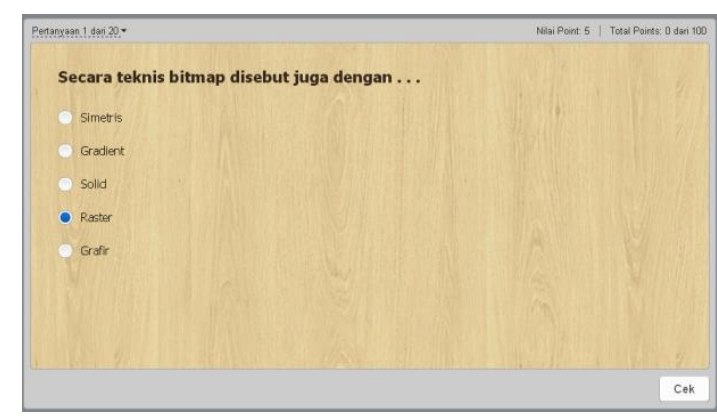

Gambar 5. Tampilan Evaluasi

Gambar 5 merupakan halaman evaluasi yang berisi soal-soal yang digunakan untuk mengukur kemampuan siswa. Soal pada media berupa pilihan ganda.

\section{Pembahasan}

Sesuai dengan tahapan yang sudah dilakukan dalam pembuatan media pembelajaran berupa media pembelajaran berbasis android, dikatakan bahwa media pembelajaran ini dikembangan sesuai dengan kurikulum mata pelajaran desain grafis kelas $\mathrm{X}$. Media pembelajaran berbasis android ini telah melalui tahapan evaluasi pramaster yang diawali dengan para ahli. Validasi atau penilaian yang dilakukan kepada ahli dapat dilihat pada Tabel 1.

Tabel 1. Hasil validasi ahli

\begin{tabular}{llll}
\hline No & Uji Kelayakan & Presentase & Ket \\
\hline 1 & Ahli Media & $82,46 \%$ & Baik \\
2 & Ahli Desain & $80,82 \%$ & Baik \\
3 & Ahli Materi & $85,40 \%$ & Baik \\
\hline
\end{tabular}


Sedangkan Tabel 2 menunjukkan hasil dari uji coba lapangan.

Tabel 2. Hasil uji coba lapangan

\begin{tabular}{llll}
\hline No & $\begin{array}{l}\text { Uji } \\
\text { Kelayakan }\end{array}$ & Presentase & Ket \\
\hline 1 & Perorangan & $94,6 \%$ & Baik \\
& & & Sekali \\
2 & Skala Kecil & $93,38 \%$ & Baik \\
& & & Sekali \\
3 & Skala Besar & $88,8 \%$ & Baik \\
& & & Sekali \\
\hline
\end{tabular}

\section{KESIMPULAN DAN SARAN}

\section{Kesimpulan}

Berdasarkan hasil penelitian dan pembahasan tentang pengembangan media pembelajaran berbasis android yaitu melalui beberapa tahap yaitu tahap uji coba ahli dan tahap uji coba ke lapangan. Hasil evaluasi ahli yang dilakukan oleh ahli media diperoleh 78,30 dengan predikat baik, evaluasi ahli desain diperoleh persentase 78 dengan predikat baik, dan ahli materi menilai produk yang dibuat dengan persentase 80 predikat baik. Jadi keseluruhan nilai rata-rata persentase pada validasi ahli memperoleh kriteria kelayakan Baik.

Setelah dilakukan uji kelayakan para ahli maka dilanjutkan dengan uji coba perorangan diperoleh rata-rata persentase 80 dengan predikat baik, uji coba skala kecil diperoleh rata-rata persentase 80,05 dengan predikat baik, dan uji coba skala besar diperoleh rata-rata persentase 80,05 dengan predikat baik. Jadi secara keseluruhan nilai rata-rata persentase pada responden memperoleh kriteria kelayakan Baik.

Berdasarkan hasil dari beberapa tahap uji coba yang dilakukan oleh ahli dan responden dapat disimpulkan bahwa media pembelajaran berbasis android ini layak diterapkan dalam pembelajaran desain grafis di kelas $\mathrm{X}$.

\section{Saran}

Berdasarkan hasil penelitian yang telah dilakukan, peneliti memberikan saran pada peneliti berikutnya, yaitu agar dapat mengembangkan dan membenahi penyusunan program pembelajaran pembelajaran berbasis android dengan bentuk soal yang lebih kompleks agar menghasilkan program yang lebih baik. Menambahkan animasi-animasi agar media pembelajaran tampak lebih menarik.

\section{DAFTAR PUSTAKA}

Borg, W. R. \& Gall, M. D. 2003. Educational research: an introduction (7th ed.). New York: Longman, Inc.

Diamar, P., Kuswanto, J., Okta, Jumdapi. 2019 "Pengembangan Media Pembelajaran Modul Interaktif Pada Mata Pelajaran PKn Kelas VIII," Baturaja Journal of Educational Technology (BaJET), Vol. 3, No. 2.

Jafnihirda, Lika., Diani, \& Sefriani, Rini. 2019. "Pengembangan Modul Pembelajaran Desain Grafis Berbasis 3D Pageflip Professional (Studi Kasus Kelas X TKJ SMK Muhammadiah 1 Padang)," Jurnal 
Pedidikan Teknologi Informasi, Vol. 6, No. 1. Hal 45-54.

Kuswanto, Joko. 2019. "Pengembangan

Media Pembelajaran Berbasis Android Pada Mata Pelajaran Biologi

Kelas XI," Indonesian Journal of Business Intelligence (IJUBI), Vol. 2, No. 2.

Kuswanto, Joko. 2019. "Pengembangan

Modul Interaktif Pada Mata Pelajaran IPA Terpadu Kelas VIII," Media Infotama, Vol. 15, No. 2.

Kuswanto, Joko. 2019."Perancangan Media Pembelajaran Model Game Mata Pelajaran Penjaskes Kelas V," SITECH, Vol. 2, No. 1.

Menrisal, \& Utami, Nadiya Rizki. 2019 "Perancangan dan Pembuatan Media Pembelajaran Android Pada Mata Pelajaran Simulasi dan Komunikasi Digital (Studi Kasus Kelas X SMKN 7 Kerinci)," Media Infotama, Vol. 6, No. 1. Hal 1-11.

Puspitaningrum, Asti Amalina, dkk. 2019."Pengembangan Media Pembelajaran Berbasis Android Pada Materi Routing Statis," Jurnal Ilmiah Edutic, Vol. 6, No. 1.

Putra, Nusa. 2011. "Research \& Development Penelitian dan Pengembangan: Suatu Pengantar." Jakarta: Rajawali Pers.

Sari, Dian Kartika. 2018. "Pengembangan Aplikasi Android Mobile Dictionary And Emulatorperintah Dasar Command Line Interfacelinux dan Windows". Skripsi tidak diterbitkan. Yogyakarta: Program Studi Pendidikan Teknik Informatika Universitas Negeri Yogyakarta.
Sefriani, Rini., \& Wijaya, Indra. 2018. Modul Pembelajaran Multimedia Interaktif Berbasis Adobe Director Pada Mata Pelajaran Sistem Operasi Sekolah Menengah Kejuruan. Journal of Information Technology and Computer Science (INTECOMS). Vol 1 No 1, Maret 2018, 60-71

Sudijono, Anas. 2012. Pengantar Statistik Pendidikan: Jakarta: PT Raja Grafindo Persada

Warsita, Bambang, 2008. "Teknologi Pembelajaran Landasan dan Aplikasinya.” Jakarta: Rineka Cipta. 